AperTO - Archivio Istituzionale Open Access dell'Università di Torino

\title{
Bioactive compound and antioxidant activity distribution in rollermilled and pearled fractions of conventional and pigmented wheat varieties
}

\section{This is the author's manuscript}

Original Citation:

Availability:

This version is available http://hdl.handle.net/2318/1634531

since 2022-01-07T14:39:03Z

Published version:

DOI:10.1016/j.foodchem.2017.04.065.

Terms of use:

Open Access

Anyone can freely access the full text of works made available as "Open Access". Works made available under a Creative Commons license can be used according to the terms and conditions of said license. Use of all other works requires consent of the right holder (author or publisher) if not exempted from copyright protection by the applicable law. 
This Accepted Author Manuscript (AAM) is copyrighted and published by Elsevier. It is posted here by agreement between Elsevier and the University of Turin. Changes resulting from the publishing process - such as editing, corrections, structural formatting, and other quality control mechanisms - may not be reflected in this version of the text. The definitive version of the text was subsequently published in FOOD CHEMISTRY, 233, 2017, 10.1016/j.foodchem.2017.04.065..

You may download, copy and otherwise use the AAM for non-commercial purposes provided that your license is limited by the following restrictions:

(1) You may use this AAM for non-commercial purposes only under the terms of the CC-BY-NC-ND license.

(2) The integrity of the work and identification of the author, copyright owner, and publisher must be preserved in any copy.

(3) You must attribute this AAM in the following format: Creative Commons BY-NC-ND license (http://creativecommons.org/licenses/by-nc-nd/4.0/deed.en), 10.1016/j.foodchem.2017.04.065.

When citing, please refer to the published version.

Link to this full text:

http://hdl.handle.net/2318/1634531 
1 TITLE

2 Bioactive compound and antioxidant activity distribution in roller-milled

\section{RUNNING TITLE}

Bioactives in milled and pearled fractions of conventional and pigmented wheats

\section{AUTHORS}

Debora Giordano", Monica Locatelli², Fabiano Travaglia², Matteo Bordiga ${ }^{2}$, Amedeo Reyneri $^{1}$, Jean Daniel Coïsson ${ }^{2}$, Massimo Blandino ${ }^{1 *}$

\section{AFFILIATIONS}

${ }^{1}$ Dipartimento di Scienze Agrarie, Forestali e Alimentari (DISAFA), Università di Torino, Largo Paolo Braccini 2, 10095 Grugliasco (TO), Italy.

${ }^{2}$ Dipartimento di Scienze del Farmaco and Drug and Food Biotechnology Center, Università del Piemonte Orientale "A. Avogadro", Largo Donegani 2, 28100 Novara (NO), Italy.

${ }^{*}$ Corresponding author: Massimo Blandino

Phone +39011 6708895, massimo.blandino@unito.it 


\section{ABSTRACT}

In this study, the chemical composition of pigmented wheats (yellow, purple and blue types), and the distribution of the bioactive compounds in their roller-milled and pearled fractions, were compared with conventional wheats (red and white types).

Roller-milling promoted the recovery of total dietary fiber, $\beta$-glucans, phenolic acids and anthocyanins in the bran fraction which resulted also in a higher total antioxidant activity than the refined flour. Conversely, lutein resulted mainly concentrated in the refined flour. In the same way, the distribution pattern in the pearled fractions differ depending on the bioactive considered. The study highlights that a careful selection of the most appropriate fractionation process should be performed to produce flours rich in bioactive compounds. Roller-milling resulted useful for the production of refined flours rich in xanthophylls, with particular emphasis to the yellow-grained wheats. Contrarily, pearling could be more useful in the valorization of the health potential of anthocyanin-pigmented varieties.

\section{KEYWORDS}

Pigmented wheats, Grain-fractionation technologies, Total dietary fiber, $\beta$-glucans, Antioxidant capacity, Phenolic acids, Carotenoids, Anthocyanins

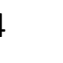

5

6

\section{7}

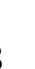
(1) so 31 52 


\section{INTRODUCTION}

Whole grain cereals are an important source of bioactive compounds, and increasing evidence from clinical and epidemiological studies suggests that the regular consumption of wheat, as whole grain, might reduce the risk of developing chronic diseases (Borowicki, Stein, Scharlau \& Glei, 2010; Fardet, 2010; Belobrajdic \& Bird, 2013).

Phenolic compounds occur abundantly in cereals, and are related to the antioxidant activity of the grain (Adom \& Liu, 2002). Phenolic acids are the main phenolic compounds in cereals, and they constitute one of the major and most complex groups of phytochemicals (Li, Shewry \& Ward, 2008). In addition to phenolic acids, other bioactive compounds with antioxidant activity, such as anthocyanins and carotenoids, may also be present in cereal kernels. Anthocyanins and carotenoids both are classified as pigments, and are responsible for the characteristic blue-purple and yellow-orange hue of kernels, respectively. The content of these phytochemicals is generally limited in conventional white- or red-grained wheat varieties (Carson \& Edwards, 2009), while they occur more consistently in the so-called pigmented varieties. These types of common wheat varieties, which are characterized by purple, blue or yellow grains, are actually produced in small amounts, but growing interest has recently been shown in the genetic development of novel pigmented varieties (Jaafar, Baron, Siebenhandl-Ehn, Rosenau, Böhmdorfer \& Grausgruber, 2013; Martinek, Škorpík, Chrpová, Fučík \& Schweiger, 2013). In fact, these unconventional varieties might be important sources of biologically active phytochemicals, and as a result, they could be valuable raw materials for the production of functional foods (Ficco et al., 2016; Li, Pickard \& Beta, 2007; Pasqualone et al., 2015).

Nevertheless, the use of wheat varieties that are naturally rich in bioactive compounds should be combined with a suitable grain processing technology, in order to preserve the bioactives and to produce functional ingredients. Previous studies, performed on conventional common wheat varieties, have shown that the bioactive compounds are 
mainly concentrated in the outer layers of the grain, and that their distribution within the kernel differs according to the class of nutrients (Sovrani et al., 2012). Consequently, the conventional roller-milling process, which promote the removal of the outer layers of the kernel in the bran fraction, causes a great decrease in the nutritional value of the refined flour (Siebenhandl et al., 2007). Another fractionation technology that was proposed as an alternative strategy to valorize the outer layers of the kernel was the pearling process (Hemery, Rouau, Lullien-Pellerin, Barron \& Abecassis, 2007). Wheat millers are increasingly using the pearling process before roller milling, since it improves the efficiency of the milling process by removing the outer layers of the kernel through an abrasive scouring (Campbell, Webb, Owens \& Scanlon, 2012). Moreover, the degree of pearling could be carefully modulated in order to separate the outermost fractions, which could be characterized by a higher content in contaminants and coarse fiber, from the intermediate fractions, which offer potentially high health benefits (Sovrani et al., 2012; Blandino et al., 2015).

The aim of this work was to characterize the chemical composition of roller-milled and pearled fractions obtained from common wheat varieties, characterized by different kernel colors (red, white, yellow, purple and blue), in order to evaluate the best fractionationtechnology able to valorize the health potential of pigmented varieties in the production of functional ingredients rich in bioactive compounds. 


\section{MATERIALS AND METHODS}

\subsection{Grain samples}

The present study has analyzed the milled and pearled fractions of five wheat varieties (Triticum aestivum L.). These wheat varieties included:

- PR22R58: red-grained wheat, provided by Pioneer Hi-Bred Italia S.r.I (Italy);

- Whitebear: white-grained wheat, provided by C\&M Seeds (Ontario);

- Bona Vita: yellow-grained wheat, provided by Osivo a. s. (Slovakia);

- Rosso: purple-grained wheat, provided by Saatbau (Austria);

- Skorpion: blue-grained wheat, provided by the Agricultural Research Institute Kromeriz, Ltd. (the Czech Republic).

\subsection{Analysis of the kernel traits}

Thousand kernel weight (TKW) was determined on three 100-kernel sets of each sample, using an electronic balance. Test weight (TW) was determined by means of a Dickey-John GAC2000 grain analysis meter (Dickey-John Corp., Auburn, IL), using the supplied program, after validation with reference materials.

\subsection{Wheat grain roller-milling and pearling}

Grain samples were processed in order to obtain both roller-milled and pearled fractions.

The roller-milled fractions were obtained using a laboratory-scale mill (Labormill 4RB, Bona, Monza, Italy), after tempering, according to the grain variety. After milling, two fractions were analyzed: the bran and the refined flour. On average, the milling yield (relative amount of refined flour) was $48 \pm 1 \%$.

Six pearled fractions of the kernels were obtained through the incremental pearling of the wheat varieties, according to the approach described by Sovrani et al. (2012). The pearling 
consisted of consecutive passages of kernels or pearled kernels in an abrasive-type grain testing mill (Model TM-05C, Satake, Tokyo, Japan). Starting from unprocessed grain samples $(5 \mathrm{~kg})$, the kernels were initially pearled to remove $5 \%$ of the original grain weight, and this resulted in a first fraction $(0-5 \% \mathrm{w} / \mathrm{w})$. The remaining kernels were then pearled to remove a second fraction of $5 \%(5-10 \% \mathrm{w} / \mathrm{w})$. The pearling process was repeated to remove a third, fourth and fifth fraction (designed fractions of $10-15 \%, 15-20 \%, 20-25 \%$ w/w). The pearling process was performed at a constant speed $(55 \mathrm{~Hz})$, thus the estimation of the time necessary in order to remove $5 \%$ of kernel weight at each pearling passage was experimentally quantified for each variety. The pearling process was then monitored by means of a time control, and after each pearling session, the laboratory pearler was cleaned thoroughly to minimize equipment contamination. The residual $75 \%$ of the kernel $(25-100 \% \mathrm{w} / \mathrm{w})$ was also collected.

The residual pearled kernels were milled by means of a laboratory centrifugal mill (Model ZM-100, Retsch, Haan, Germany) equipped with a 1-mm sieve. The same process was performed also for the unprocessed grain samples in order to obtain a wholegrain flour. Prior to the $\beta$-glucan analyses, all the samples were ground in an oscillatory mill (particle size < $500 \mu \mathrm{m}$ ) (Mixer mill MM440, Retsch GmbH, Hann, Germany), and were also sieved (particle size $<250 \mu \mathrm{m}$ ) to determine the total antioxidant activity. All the samples were stored at $-25^{\circ} \mathrm{C}$, before the chemical analyses were performed.

\subsection{Chemical analyses}

\subsubsection{Chemicals}

Acetonitrile (CHROMASOLV®Plus, $\geq 99.9 \%$ ), dichloromethane (CHROMASOLV®, 299.9\%), 2,2-diphenyl-1-picrylhydrazyl (DPPH), 2,6-di-tert-butyl-4-methylphenol (BHT, $\geq 99.0 \%$ ), ethanol (CHROMASOLV®, $\geq 99.8 \%$ ), ethyl acetate (CHROMASOLV®, $\geq 99.8 \%$ ), formic acid $(\geq 95.0 \%)$, hexane (CHROMASOLV®, $\geq 97.0 \%)$, ( \pm )-6-hydroxy-2,5,7,8- 
150 tetramethylchromane-2-carboxylic acid (Trolox, 97\%), hydrochloric acid $(\mathrm{HCl}, 37.0 \%)$, 151 methanol (CHROMASOLV®, $\geq 99.9 \%$ ), potassium hydroxide $(\mathrm{KOH}, 90.0 \%)$, sodium 152 hydroxide $(\mathrm{NaOH}, \geq 98.0 \%)$, tert-butyl methyl ether (MTBE, CHROMASOLV®, $\geq 99.9 \%$ ) 153 and phenolic acid standards (caffeic acid $\geq 98 \%$, chlorogenic acid $\geq 95 \%$, ellagic acid $\geq 95 \%$, $154 p$-hydroxybenzoic acid $\geq 99 \%, p$-coumaric acid $\geq 98 \%$, protocatechuic acid $\geq 97 \%$, sinapic 155 acid $\geq 98 \%$, syringic acid $\geq 95 \%$, trans-ferulic acid $\geq 99 \%$ and vanillic acid $\geq 97 \%$ ) were purchased from Sigma-Aldrich (St. Louis, Missouri, US). Anthocyanin standards (cyanidin3-O-glucoside, delphinidin-3-O-glucoside and peonidin-3-O-glucoside) and carotenoid standards (lutein, zeaxanthin, $\beta$-cryptoxanthin and $\beta$-carotene) were purchased from Extrasynthese (Lyon, France).

\subsubsection{Proximate composition analysis}

162

The moisture content, determined in order to express the results on a dry weight (dw) basis, was obtained using a Sartorius MA30 thermo-balance (Sartorius AG, Goettingen, Germany). The total nitrogen content and total protein content (conversion factor: 5.70) were obtained according to the Kjeldahl method by means of a Kjeltec system I (Foss Tecator AB, Höganäs, Sweden). The ash content was determined in a muffle furnace according to the AOAC (1990) procedure. The total dietary fiber (TDF) and $\beta$-glucan contents were determined by means of the Megazyme total dietary fiber analysis kit and the Megazyme mixed-linkage $\beta$-glucan assay kit, respectively.

\subsubsection{Determination of the Total Antioxidant Activity (TAA)}

TAA was determined employing DPPH radical scavenging method (direct measurement on solid samples), as previously described in (Sovrani et al., 2012). Samples were opportunely weighed $(0.5-20 \mathrm{mg}$, to obtain a final inhibition percentage in the $35-65 \%$ 
range); then, $700 \mu \mathrm{l}$ of water and $700 \mu \mathrm{l}$ of a DPPH methanolic solution $(100 \mu \mathrm{M})$ were added. The reaction was carried out in the dark under stirring at $20^{\circ} \mathrm{C}$ and $1000 \mathrm{rpm}$ (Thermomixer comfort, Eppendorf, Germany) for 25 min. The samples were promptly centrifuged for 1 minute at $17530 \mathrm{~g}$, and the absorbance was measured at $515 \mathrm{~nm}$ after exactly 30 minutes. A control solution, without the ground sample, was tested under the same conditions, in order to calculate the DPPH inhibition percentage of the samples. The final results were expressed as mmol of Trolox equivalents (TE)/kg of sample (dw) through a calibration curve (linearity range: $2.8-33.5 \mathrm{nmol} ; \mathrm{r}^{2}$ : 0.982).

\subsubsection{Extraction of the free and bound phenolic acids and quantification by means of} RP-HPLCIDAD

Fifty milligrams of each sample were suspended in $1 \mathrm{~mL}$ of a methanol:water 80:20 (v/v) mixture, vortexed for $10 \mathrm{sec}$, and then extracted in an ultrasonic bath (Bransonic 1510, output $42 \mathrm{kHz}$, Branson Ultrasonics, Danbury, CT) for 2 min. The extracts were centrifuged at $17530 \mathrm{~g}$ for $2 \mathrm{~min}$, and pellets were extracted another two times, according to the method described above. The supernatants were collected and used for the chromatographic analyses of the free phenolic acids.

The pellet remaining after the extraction of the free phenolic acids was hydrolyzed for 3.5 hours under a nitrogen stream, and in continuous agitation, by adding $10 \mathrm{~mL} \mathrm{NaOH} 1 \mathrm{M}$. After acidification to $\mathrm{pH} 2.3$ with $\mathrm{HCl}$, the bound phenolic acids were extracted with $20 \mathrm{~mL}$ of ethyl acetate. The extraction was repeated three times. The combined supernatants were evaporated to dryness, and then reconstituted in $2 \mathrm{~mL}$ of methanol.

The extracts were centrifuged at $17530 \mathrm{~g}$ for $2 \mathrm{~min}$, and analyzed using an HPLC system (Shimadzu LC-20A Prominence, Shimadzu Italia, Milan, Italy), coupled to a SPD-M20A diode array detector. Separations were carried out using a $150 \times 2 \mathrm{~mm}, 5 \mu \mathrm{m}$, Luna C18(2) column (Phenomenex, Torrance, CA), protected by a guard column containing the same 
phase; the column temperature was set at $30^{\circ} \mathrm{C}$. The mobile phase consisted of $0.1 \% \mathrm{v} / \mathrm{v}$ formic acid in water (solvent $A$ ) and $0.1 \% \mathrm{v} / \mathrm{v}$ formic acid in methanol (solvent $\mathrm{B}$ ), and the following operating gradient was used: 0-30 $\mathrm{min}, 5-17.5 \% \mathrm{~B} ; 30-40 \mathrm{~min}, 17.5-30 \% \mathrm{~B}$; 40was followed by 15 minutes of equilibration. The mobile phase flow rate was $0.4 \mathrm{~mL} / \mathrm{min}$, and the injection volume was $20 \mu \mathrm{L}$ for the free phenolic acid extracts and $1 \mu \mathrm{L}$ for the bound phenolic acid extracts. The hydroxycinnamic acids (ferulic acid, caffeic acid, $p$ coumaric acid, sinapic acid, chlorogenic acid) and hydroxybenzoic acids (vanillic acid, $p$ hydroxybenzoic acid, protocatechuic acid, ellagic acid, syringic acid) were identified using the retention times and UV/Vis spectra of their respective standards. Phenolic acid standards were prepared and diluted to different concentrations, in order to obtain calibration curves for quantification purposes. The hydroxycinnamic acids and hydroxybenzoic acids were quantified at $330 \mathrm{~nm}$ and $280 \mathrm{~nm}$, using ferulic acid and protocathecuic acid as reference compounds, respectively (injection volume: $1 \mu \mathrm{L}$; linearity range: $0.05-5 \mu \mathrm{g} / \mathrm{mL}$ for hydroxycinnamic acids [5-300 $\mu \mathrm{g} / \mathrm{mL}$ in the case of bound ferulic acid]; 0.5-10 $\mu \mathrm{g} / \mathrm{mL}$ for hydroxybenzoic acids).

\subsubsection{Extraction of the anthocyanins and quantification by means of RP-HPLC/DAD}

Each sample $(1 \mathrm{~g})$ was extracted using $8 \mathrm{~mL}$ of ethanol acidified with $\mathrm{HCl} 1 \mathrm{~N}(85: 15, \mathrm{v} / \mathrm{v})$ for $30 \mathrm{~min}$. The absorbance was measured after centrifugation at $17530 \mathrm{~g}$ for $2 \mathrm{~min}$ at 540 nm, as reported by Siebenhandl et al. (2007). The total Anthocyanin Content (TAC) was expressed as mg cyanidin-3-O-glucoside (Cy-3-glc) equivalents/kg of sample (dw).

The identification and quantification of the individual anthocyanins was performed using the previously described chromatographic system. Separations were carried out using a $250 \times 4.6 \mathrm{~mm}, 4 \mu \mathrm{m}$, RP SynergiTM $4 \mu \mathrm{m}$ Max-RP $80 \AA$ LC Column (Phenomenex, Torrance, CA), protected by a guard column containing the same phase; the column 
temperature was set at $30^{\circ} \mathrm{C}$. The mobile phase consisted of water:formic acid:acetonitrile [87:10:3, v/v; (solvent A)] and water:formic acid:acetonitrile [40:10:50, v/v; (solvent B)], and the following operating gradient was used: $0-20 \mathrm{~min}, 6-20 \% \mathrm{~B} ; 20-35 \mathrm{~min}, 20-40 \% \mathrm{~B} ; 35-$ 40 min, $40-60 \%$ B; $40-45$ min, $60-90 \%$ B; $45-50$ min isocratic $90 \%$ B. Finally, the mobile phase was brought to $6 \% \mathrm{~B}$ in 0.5 minutes, and this was followed by 22.5 minutes of equilibration. The mobile phase flow rate was $0.5 \mathrm{~mL} / \mathrm{min}$, and the injection volume was 15 $\mu \mathrm{L}$. Cyanidin-3-O-glucoside, delphinidin-3-O-glucoside and peonidin-3-O-glucoside were identified using the retention times and UV/Vis spectra of the individual authentic standard molecules; delphinidin-3-O-rutinoside, cyanidin-3-O-rutinoside and peonidin-3-O-rutinoside were identified on the basis of literature data (Abdel-Aal, Young, \& Rabalski, 2006; AbdelAal, Abou-Arab, Gamel, Hucl, Young, \& Rabalski, 2008; Knievel, Abdel-Aal, Rabalski, Nakamura \& Hucl, 2009; Liu, Qiu \& Beta, 2010). Quantification of the individual compounds was performed at $520 \mathrm{~nm}$, using glucoside forms of anthocyanins (rutinosides were quantified as equivalents of the corresponding glucosides); calibration curves were obtained at six different concentration levels (injection volume: $5 \mu \mathrm{L}$; linearity range: $0.005-$ $10 \mu \mathrm{g} / \mathrm{mL})$.

\subsubsection{Extraction of the carotenoids and quantification by means of RP-HPLC/DAD}

Each sample $(0.3 \mathrm{~g})$ was extracted for $6 \mathrm{~min}$ at $85^{\circ} \mathrm{C}$ with $95 \%$ ethanol, containing $1 \mathrm{~g} / \mathrm{L}$ $\mathrm{BHT}$. The extracts, including solids, were hydrolyzed with $125 \mu \mathrm{L}$ of $\mathrm{KOH}(1 \mathrm{~g} / \mathrm{mL})$ at $85^{\circ} \mathrm{C}$ for $10 \mathrm{~min}$, chilled on ice and $3 \mathrm{~mL}$ of cold deionized water was then added. This was followed by the addition of $3 \mathrm{~mL}$ of hexane, containing $1 \mathrm{~g} / \mathrm{L} \mathrm{BHT}$. The test tubes were then vortexed and centrifuged at $1200 \mathrm{~g}$ for 10 minutes. The extraction was repeated four times, and the combined supernatants were evaporated to dryness under a nitrogen stream, and then reconstituted in $75 \mu \mathrm{L}$ of dichloromethane. 
252 The extracts were analyzed by means of a high performance liquid chromatograph Agilent 2531200 Series (Agilent Technologies, Santa Clara, CA, USA) coupled to an Agilent 1200 254 Series diode array detector. Separations were carried out using a $250 \times 4.6 \mathrm{~mm}, 3 \mu \mathrm{m}$, 255 C30 carotenoid YMC column (YMC Co., Kyoto, Japan); the column temperature was set at $25^{\circ} \mathrm{C}$. The mobile phase consisted of methanol:MTBE:water [81:15:4, v/v; (solvent A)] and MTBE:methanol [91:9, v/v; (solvent B)]. The following operating linear gradient was used: in 10 minutes, and this was followed by 15 minutes of equilibration. The flow rate of the mobile phase was $1.0 \mathrm{~mL} / \mathrm{min}$, and the injection volume was $5 \mu \mathrm{L}$. Carotenoids were identified using the retention times and the UV/Vis spectra of their respective standards (lutein, zeaxanthin, $\beta$-cryptoxanthin and $\beta$-carotene). Carotenoid standards were also prepared and diluted to different concentrations to obtain calibration curves for quantification purposes (linearity range: $0.1-100 \mu \mathrm{g} / \mathrm{mL}$ for lutein and zeaxanthin; 0.3-40 $\mu \mathrm{g} / \mathrm{mL}$ for $\beta$-cryptoxanthin and $\beta$-carotene). The quantifications were performed at $450 \mathrm{~nm}$.

\subsection{Color analyses}

The chromatic analyses were performed using a Minolta Chroma Meter reflectance spectrophotometer (Model CR-400, Minolta Co., Osaka, Japan). A 45 mm diameter Petri dish was loosely filled with a ground subsample, and the dish was then tapped gently until the sample was levelled and no gaps were apparent through the base of the dish. The $L^{*}$, $a^{*}$ and $b^{*}$ color values were determined directly by the instrument.

\subsection{Statistical analyses}

All the analyses were performed at least in triplicate checking that the variation coefficient was lower than $10 \%$. One-way analysis of variance (ANOVA) was applied in order to 
277 compare the contents of the bioactive compounds in wholegrain flours on the basis of the 278 wheat genotype, and in the different roller-milled and pearled fractions of each wheat type. 279 The REGW-Q test was performed for multiple comparisons. A 0.05 threshold was used to 280 reject the null hypothesis.

281 Statistical analyses were carried out by means of SPSS for Windows statistical package, 282 Version 22.0 (SPSS Inc., Chicago, Illinois).

283 


\section{RESULTS AND DISCUSSION}

\subsection{Kernel traits and the bioactive compound contents of the wholegrain flours}

Although the most commonly cultivated wheat varieties are the red- and white-grained ones, the application of pigmented wheat varieties for the production of functional foods has drawn the attention of both researchers and the food industry in the last few years (Ficco et al., 2016; Li et al., 2007; Pasqualone et al., 2015; Yu \& Beta, 2015; Zanoletti et al., 2017). In this study the chemical composition of pigmented wheat varieties (yellow, purple and blue types) was analyzed and compared with conventional wheat varieties (red and white types). The compared cultivars showed differences both in their physical characteristics, in the chemical content and in the color of their wholegrain flours (Table 1 and 2).

The wholegrain flour of pigmented wheat varieties showed levels of total dietary fiber (TDF), $\beta$-glucans, total antioxidant activity (TAA), free (FPAs) and cell wall-bound (CWBPAs) phenolic acids similar to the ones of conventional wheat varieties, as well as significant concentrations of anthocyanins and xanthophylls, which were absent or limited in the red- and white-grained varieties. As far as the anthocyanin-pigmented varieties are concerned, the purple type showed a higher overall total anthocyanin content (TAC) than the blue one. The main carotenoid detected in all the samples was lutein, and this was followed by zeaxathin, while $\beta$-cryptoxantin and $\beta$-carotene were not detected. The concentration of lutein was on average 6.6 times higher than that of zeaxanthin, and the yellow variety was the one characterized by the highest content of this xanthophyll. The chromatic characteristics of the wholegrain flours of both the conventional and pigmented varieties were determined in order to demonstrate that the analyzed grains differed in their color. As expected, the different bioactive compound profiles resulted in significant differences in the lightness $\left(L^{*}\right)$, and in the red $\left(a^{*}\right)$ and blue $\left(b^{*}\right)$ indexes of the wholegrain flour (Table 2). The wholegrain flour of the white variety was characterized by 
the highest lightness value and the lowest redness one. Differently, the purple and the blue varieties showed the lowest lightness value, and were characterized by the highest redness and blueness values, respectively. The wholegrain flour of the yellow variety was characterized by the highest yellowness, in accordance with its high lutein content.

\section{$\underline{3.2 \text { Bioactive compound distribution in the roller-milled fractions }}$}

The analysis of the roller-milled fractions clearly shows that the bioactive compounds are unevenly distributed in the kernels of both conventional and pigmented wheat varieties (Table 3). In particular, roller-milling promoted the recovery of proteins, TDF, $\beta$-glucans, FPAs and CWBPAs in the bran fraction. Consequently, regardless the variety considered the bran fraction resulted in a TAA 10 and 3 times higher than the one of the refined flour and the wholegrain flour, respectively. This result was in accordance with previous studies that mainly ascribe TAA of wheat grains to phenolic compounds (Beta, Nam, Dexter \& Sapirstein, 2005). As far as the individual phenolic acids are concerned, only free and bound ferulic acid and bound ellagic acid were identified in the refined flour, while a more complex profile was observed in the bran fraction (the main phenolic acids quantified are reported in Table S1). Considering the two anthocyanin-pigmented varieties, their bran fraction was characterized on average by a total anthocyanin content 23 and 2 times higher than the one of the refined flour and the wholegrain flour, respectively. Not many data are currently available on the distribution of carotenoids in wheat kernels. Previously, it has been observed that lutein was concentrated more in the endosperm than in the bran of einkorn and durum wheat, while the opposite trend has been observed in common wheat (Abdel-Aal, Young, Rabalski, Hucl \& Fregeau-Reid, 2007). Conversely, Siebenhandl et al. (2007) observed a higher concentration of total carotenoids in the refined flour than in the bran fraction of a blue-grained wheat variety. In the present study, lutein was always mainly concentrated in the refined flour than in the bran fraction, with the only exception 
being the blue variety, which did not show any significant difference between its rollermilled fractions. As far as the yellow-grained variety is concerned, the concentration of lutein observed in the refined flour is slightly higher $(+12 \%)$ than the one observed in the wholegrain flour. Zeaxanthin, whose concentration was always lower than that of lutein, showed an opposite distribution pattern.

In accordance with the composition and distribution of bioactive compounds, regardless the variety considered the bran fraction showed lower lightness and higher redness values than the refined flour (Table S2).

The present study clearly confirms that the roller-milling process results in the concentration of the most nutritional compounds in the bran fraction of both conventional and pigmented wheat varieties. This result is particularly relevant for the anthocyaninpigmented wheat varieties because of the removal of most of the anthocyanins in the bran fraction. Several studies proposed the use of the wheat bran of both conventional (Sobota, Rzedzicki, Zarzycki \& Kuzawińska, 2015) and pigmented wheat varieties (Li et al., 2007) for the production of cereal-derived products enriched in bioactive compounds. At the same time, roller-milling removes the parts of the grain known or suspected to be detrimental to foods, in relation to safety, processing and acceptability by the consumers (Zhang \& Moore, 1999; Cheli et al., 2010). Thus, especially for anthocyanin-pigmented varieties, instead of reject or maintain totally the bran fraction, greater attention needs to be paid to optimize the processing of kernels in order to ensure bioactive preservation and at the same time the removal of the fractions suspected to be detrimental for food production.

Contrarily to all the other bioactive compounds analyzed in the present study, lutein resulted mainly concentrated in the refined flour than in the bran fraction. Thus, the application of the conventional roller-milling process could be considered useful for the 
production of refined flours naturally rich in xanthophylls, with particular emphasis to the yellow-grained varieties.

\subsection{Bioactive compound distribution in the pearled fractions}

In agreement with data observed for the roller-milled fractions, the analyses performed on pearled fractions showed an unevenly distribution of bioactive compounds in the grains of both conventional and pigmented wheat varieties. Moreover, the distribution patterns in the pearled fractions differ depending on the class of bioactive considered (Table 4).

In accordance with previous studies (Jerkovic, Kriegel, Brander, Atwell, Roberts \& Willows, 2010; Sovrani et al., 2012), the protein and $\beta$-glucan contents were found to be higher in the intermediate pearled fractions of all the varieties. Contrarily, the TDF, TAA, FPAs and CWBPAs were generally detected at the highest concentration in the outermost layers of the kernel, and decreased moving toward the inner layers. Individual phenolic compounds, in both free and cell wall-bound form, generally presented the highest content in the first two pearling fractions (corresponding to the $0-10 \%$ of the kernel weight). The main compounds identified and their relative content was quite similar in the different wheat varieties; the bound form of ferulic acid resulted the most representative (Table S3). Similar distribution patterns were previously observed in the pearled fraction of conventional wheat varieties (Sovrani et al., 2012). The TAA in the first two pearled fractions, which correspond to the outermost layers of the kernels, resulted similar to the one observed in the bran fraction and even 3 times higher than the one observed in the wholegrain flour.

The distribution patterns of total anthocyanins in the purple and blue varieties are shown in Figure 1. Anthocyanins were found to be located in specific layers of the kernel. In particular, the purple-grained variety was characterized by the highest TAC in the $0-5 \%$ fraction (579 mg Cy-3-glc equivalents/kg dw). The total anthocyanin content of this fraction 
resulted about 6 times higher than the one observed in the wholegrain flour, and even 2 times higher than the one observed in the bran fraction. The second $5-10 \%$ pearled fraction still showed a high TAC (425 mg Cy-3-glc equivalents/kg dw), about 4 and 1.5 times higher than the one observed in the wholegrain flour and in the bran fraction. The blue-grained variety showed the highest total anthocyanin content in the $10-15 \%$ fraction (211 mg Cy-3-glc equivalents/kg dw), about 3 and 1.5 times higher than the one observed in the wholegrain flour and in the bran fraction. In accordance to previous studies (Bottega, Caramanico, Lucisano, Mariotti, Franzetti \& Pagani, 2009; Jerkovic et al., 2010; Shetlar, Rankin, Lyman \& France, 1947; Singh \& Singh, 2010; Sovrani et al., 2012), pearling up to the $5 \%$ level on average remove most of the outer pericarp, while at $5-10 \%$ and $10-15 \%$ levels the aleurone layer is removed. Thus, the results were in agreement with previous studies that showed that anthocyanins are mainly concentrated in the pericarp and in the aleurone layer on purple- and blue-grained varieties, respectively (Abdel-Aal \& Hucl, 1999; Zeven, 1991).

The analysis of individual anthocyanins (Table 5) showed that the two varieties differ not only for the total anthocyanin content, but also for the anthocyanin profile. The results were in accordance with previous studies performed on other pigmented varieties (Bartl et al., 2015; Knievel et al., 2009). The main anthocyanins in the purple wheat were peonidin and cyanidin glycosides, while delphinidin glycosides were not detected. Contrarily, the main anthocyanins detected in the blue-grained variety were delphinidin-3-O-rutinoside and cyanidin-3-O-rutinoside, although cyanidin-3-O-glucoside, delphynidin-3-O-glucoside and peonidin-3-O-rutinoside were also present. These results make possible assume that the difference observed in the color of these two varieties could be probably ascribed not only to different anthocyanin concentrations, but also to the different compositional profiles. In fact, delphinidin glycosides, which are responsible for a characteristic blue color, were only 
detected in the blue-grained variety, while cyanidin and peonidin glycosides were detected above all in the purple-grained variety.

In accordance with the distribution observed in the roller-milled fractions, lutein was found to be mainly concentrated in the internal layers of the kernel. Regardless the variety considered, the concentration of lutein in the residual pearled kernel resulted similar to the one observed in the refined flour. Contrarily, the distribution of zeaxanthin changed according to which variety was considered.

Pearled fractions showed significant difference in their chromatic characteristics as observed for the roller-milled fractions (Table S4).

Previous studies proposed the pearling process as an alternative technology in order to select and valorize the intermediated fractions of conventional red-grained varieties, which are rich in bioactive compounds, allowing at the same time the removal of the parts of the grain that could be detrimental for technological quality and safety (Liyana-Pathirana, C., Dexter, J., \& Shahidi F., 2006; Delcour, Rouau, Courtin, Poutanen \& Ranieri, 2012; Sovrani et al., 2012). The present study shows that this technology could be applied indifferently both to conventional and pigmented wheat varieties in order to concentrate the bioactive compounds, such as TDF, $\beta$-glucans and phenolic acids, that are generally present in the outer layers of all the wheat kernels. Moreover, this study shows that the use of the pearling process could be the best way in order to enhance the exploitation of the health-promoting potential of purple- and blue-grained cereals, by means of a selection of anthocyanin-rich fractions. The resultant fractions could be mixed with a refined flour to incorporate as much as bioactive compounds in a final ingredient which could be used for the production of both baked products (Blandino et al., 2013; Blandino et al., 2015) and pasta (Zanoletti et al., 2017). 


\section{CONCLUSIONS}

439 This study highlights that even if pigmented wheat varieties are an excellent source of 440 bioactive compounds, a careful selection of the most appropriate fractionation process 441 should be performed in order to produce flours naturally rich in bioactive compounds. In

442 fact, the application of the same process to different types of wheat varieties could lead to 443 conflicting results. The conventional roller-milling process could be useful to produce a 444 refined flour rich in lutein starting from yellow-grained varieties. On the contrary, the same 445 process applied to anthocyanin-pigmented varieties results in the loss of the main health 446 benefits associated to the use of these varieties, because of the removal of most of the 447 anthocyanins from the refined flour. The pearling process could be a much more useful 448 tool in order to valorize the latter varieties.

449 Further studies will be necessary for the development of supply chains based on 450 pigmented wheat varieties, in order to understand whether these varieties could be able to 451 compete with conventional ones in terms of yields and quality performance. Finally, pilot 452 and industrial scale tests should be performed in order to evaluate the potential application 453 of the pearling process to anthocyanin-pigmented varieties in order to produce new 454 ingredients with added value for consumer health. 
456 The authors would like to thank Francesca Vanara (Università of Torino), Valentina 457 Azzurra Papillo and Stefania Monteduro (Università del Piemonte Orientale "A. 458 Avogadro"), for their precious help and cooperation in the laboratory work.

459

461 This work was supported by the Regione Piemonte (Rural Development Programme 462 F.E.A.S.R. 2007/2013), as a part of the INNOBRAN project. 


\section{REFERENCES}

Abdel-Aal, E. -S. M., Abou-Arab, A. A., Gamel, T. H., Hucl, P., Young, J. C., \& Rabalski, I. (2008). Fractionation of blue wheat anthocyanin compounds and their contribution to antioxidant properties. Journal of Agricultural and Food Chemistry, 56, 11171-11177.

Abdel-Aal, E. -S. M., \& Hucl, P. (1999). A rapid method for quantifying total anthocyanins in blue aleurone and purple pericarp wheats. Cereal Chemistry, 76, 350-354.

Abdel-Aal, E. -S. M., Young, J. C., \& Rabalski, I. (2006). Anthocyanin composition in black, blue, pink, purple, and red cereal grains. Journal of Agricultural and Food Chemistry, 54, 4696-4704.

Abdel-Aal, E. -S. M., Young, J. C., Rabalski, I., Hucl, P., \& Fregeau-Reid, J. (2007). Identification and quantification of seed carotenoids in selected wheat species. Journal of Agricultural and Food Chemistry, 55, 787-794.

Adom, K. K., \& Liu, R. H. (2002). Antioxidant activity of grains. Journal of Agricultural and Food Chemistry, 50, 6182-6187.

AOAC (1990). Official Methods of Analysis, $15^{\text {th }}$ ed., Arlington, VA: Association of Official Analytical Chemists.

Bartl, P., Albreht, A., Skrt, M., Tremlová, B., Oštádalova, M., Šmejkal, K., Vovk, I., \& Ulrih, N. P. (2015). Anthocyanins in purple and blue wheat grains and in resulting bread: quantity, composition, and thermal stability. International Journal of Food Science and Nutrition, 66, 514-519.

Belobrajdic, D. P., \& Bird, A. R. (2013). The potential role of phytochemicals in wholegrain cereals for the prevention of type-2 diabetes. Nutrition Journal, 12, 62-74.

Beta, T., Nam, S., Dexter, J. E., \& Sapirstein, H. D. (2005). Phenolic content and antioxidant activity of pearled wheat and roller-milled fractions. Cereal Chemistry, 82, 390393. 
506

507

508

509

510

511

512

513

514

515

516

517

518

519

520

521

522

523

524

525

526

527

528

529

530

Blandino M., Sovrani V., Marinaccio F., Reyneri A., Rolle L., Giacosa S., Locatelli M., Bordiga M., Travaglia F., Coïsson, J. D., \& Arlorio M. (2013). Nutritional and technological quality of bread enriched with an intermediated pearled fraction. Food Chemistry, 141, 2549-2557.

Blandino, M., Locatelli, M., Sovrani, V., Coïsson, J. D., Rolle, L., Travaglia, F., Giacosa, S., Bordiga M., Scarpino, V., Reyneri, A., \& Arlorio, M. (2015). Progressive pearling of barley kernel: chemical characterization of pearling fractions and effect of their inclusion on the nutritional and technological properties of wheat bread. Journal of Agricultural and Food Chemistry, 63, 5875-5884.

Borowicki, A., Stein, K., Scharlau, D., \& Glei, M. (2010). Fermentation supernatants of wheat (Triticum aestivum L.) aleurone beneficially modulate cancer progression in human colon cells. Journal of Agricultural and Food Chemistry, 58, 2001-2007.

Bottega, G., Caramanico, R., Lucisano, M., Mariotti, M., Franzetti, L., \& Pagani M. A. (2009). The debranning of common wheat (Triticum aestivum L.) with innovative abrasive rolls. Journal of Food Engineering, 94, 75-82.

Campbell, G. M., Webb, C., Owens, G. W., \& Scanlon, M. G. (2012). Milling and flour quality. In S. P. Cauvain (Ed.), Breadmaking - Improving quality, $2^{\text {nd }}$ ed. (pp. 188-215). Cambridge: Woodhead Publishing.

Carson, G. R., \& Edwards N. M. (2009). Criteria of wheat and flour quality. In K. Khan, \& P. R. Shewry (Eds.), Wheat. Chemistry and Technology, $4^{\text {th }}$ ed. (pp.97-118). Minnesota: AACC International. Inc.

Cheli, F., Campagnoli, A., Ventura, V., Brera, C., Berdini, C., Palmaccio, E., \& Dell'Orto, V. (2010). Effects of industrial processing on the distributions of deoxynivalenol, cadmium and lead in durum wheat milling fractions. LWT - Food Science and Technology, 43, 10501057. 
Delcour J. A., Rouau X., Courtin C. M., Poutanen K., \& Ranieri R. (2012). Technologies for enhanced exploitation of the health-promoting potential of cereals. Trends in Food Science \& Technology, 25, 78-86.

Fardet, A. (2010). New hypotheses for the health-protective mechanisms of whole-grain cereals: what is beyond fibre? Nutrition Research Reviews, 23, 65-134.

Ficco, D. B. M., De Simone, V., De Leonardis, A. M., Giovaniello, V., Del Nobile, M. A., Padalino, L., Lecce, L., Borrelli, G. M., \& De Vita, P. (2016). Use of purple durum wheat to produce naturally functional fresh and dry pasta. Food Chemistry, 205, 187-195.

Hemery, Y., Rouau, X., Lullien-Pellerin, V., Barron, C., \& Abecassis, J. (2007). Dry processes to develop wheat fractions and products with enhanced nutritional quality. Journal of Cereal Science, 46, 327-347.

Jaafar, S. N. S., Baron, J., Siebenhandl-Ehn, S., Rosenau, T., Böhmdorfer, S., \& Grausgruber, H. (2013). Increased anthocyanin content in purple pericarp x blue aleurone wheat crosses. Plant Breeding, 132, 546-552.

Jerkovic, A., Kriegel, A. M., Brander, J. R., Atwell, B. J., Roberts, T. H., \& Willows, R. D. (2010). Strategic distribution of protective proteins within bran layers of wheat protects the nutrient-rich endosperm. Plant Physiology, 152, 1459-1470.

Knievel, D. C., Abdel-Aal, E. -S. M., Rabalski, I., Nakamura, T., \& Hucl, P. (2009). Grain color development and the inheritance of high anthocyanin blue aleurone and purple pericarp in spring wheat (Triticum aestivum L.). Journal of Cereal Science, 50, 113-120.

Li, W., Pickard, M. D., \& Beta, T. (2007). Effect of thermal processing on antioxidant properties of purple wheat bran. Food Chemistry, 104, 1080-1086.

Li, L., Shewry, P. R., \& Ward, J. L. (2008). Phenolic acids in wheat varieties in the HEALTHGRAIN diversity screen. Journal of Agricultural and Food Chemistry, 56, 97329739. 
Liu, Q., Qiu, Y., \& Beta, T. (2010). Comparison of antioxidant activities of different colored wheat grains and analysis of phenolic compounds. Journal of Agricultural and Food Chemistry, 58, 9235-9241.

Liyana-Pathirana, C., Dexter, J., \& Shahidi, F. (2006). Antioxidant properties of wheat as affected by pearling. Journal of Agricultural and Food Chemistry, 54, 6177-6184.

Martinek P., Škorpík M., Chrpová J., Fučík P., \& Schweiger J. (2013). Development of the new winter wheat variety Skorpion with blue grain. Czech Journal of Genetics \& Plant Breeding, 49, 90-94.

Pasqualone, A., Bianco, A. M., Paradiso, V. M., Summo, C., Gambacorta, G., Caponio, F., \& Blanco, A. (2015). Production and characterization of functional biscuits obtained from purple wheat. Food Chemistry, 180, 64-70.

Shetlar, M. R., Rankin, G. T., Lyman, J. F., \& France, W. G. (1947). Investigation of the proximate chemical composition of the separate bran layers of wheat. Cereal Chemistry, $24,111-122$.

Siebenhandl, S., Grausgruber, H., Pellegrini, N., Del Rio, D., Fogliano, V., Pernice, R., \& Berghofer, E. (2007). Phytochemical profile of main antioxidants in different fractions of purple and blue wheat, and black barley. Journal of Agricultural and Food Chemistry, 55, 8541-8547.

Singh, S., \& Singh, N. (2010). Effect of debranning on the physico-chemical, cooking, pasting and textural properties of common and durum wheat varieties. Food Research International, 43, 2277-2283.

Sobota, A., Rzedzicki, Z., Zarzycki, P., \& Kuzawińska, E. (2015). Application of common wheat bran for the industrial production of high-fibre pasta. International Journal of Food Science and Technology, 50, 111-119.

Sovrani, V., Blandino, M., Scarpino, V., Reyneri, A., Coïsson, J. D., Travaglia, F., Locatelli, M., Bordiga, M., Montella, R., \& Arlorio, M. (2012). Bioactive compound content, 
582 antioxidant activity, deoxynivalenol and heavy metal contamination of pearled wheat 583 fractions. Food Chemistry, 135, 39-46.

584 Yu, L., \& Beta, T. (2015). Identification and antioxidant properties of phenolic compounds 585 during production of bread from purple wheat grains. Molecules, 20, 15525-15549.

586 Zanoletti, M., Parizad, P. A., Lavelli, V., Checchini, C., Menesatti, P., Marti, A., \& Pagani, 587 M. A. (2017). Debranning of purple wheat: recovery of anthocyanin-rich fractions and their 588 use in pasta production. LWT - Food Science and Technology, 75, 663-669.

589 Zeven, A. C. (1991). Wheats with purple and blue grains: a review. Euphytica, 56, 243590258.

591 Zhang, D., \& Moore, W. R. (1999). Wheat bran particle size effects on bread baking 592 performance and quality. Journal of the Science of Food and Agriculture, 79, 805-809. 
595 Figure 1. The TAC in the pearled fractions of the purple (cv. Rosso) and the blue (cv. Skorpion) wheat varieties. The results are 596 expressed on a dw basis. The reported data are the means of three values; values with different letters differ significantly, according to 597 the REGW-Q test (the ANOVA level of significance is $<0.001$ ). 
600 Table 1. Kernel traits and chemical composition of the wholegrain flours of conventional and pigmented wheat varieties.

\begin{tabular}{|c|c|c|c|c|c|c|c|c|c|c|c|c|c|c|c|}
\hline \multirow{3}{*}{$\begin{array}{l}\text { Wheat } \\
\text { type } \\
\text { Red }\end{array}$} & \multirow{3}{*}{$\begin{array}{l}\begin{array}{l}\text { Variety } \\
\text { name }\end{array} \\
\text { PR22R58 }\end{array}$} & \multirow{2}{*}{$\begin{array}{l}\text { TKW } \\
\mathrm{g}\end{array}$} & TW & Proteins & Ash & TDF & $\beta$-glucans & \multirow{2}{*}{$\begin{array}{l}\text { TAA } \\
\text { mmol } \\
\text { TE/kg }\end{array}$} & \multirow{2}{*}{$\begin{array}{l}\mathrm{FPAs}^{1} \\
\mathrm{mg} / \mathrm{kg}\end{array}$} & \multirow{2}{*}{\multicolumn{2}{|c|}{$\begin{array}{l}\text { CWBPAs }^{2} \\
\mathrm{mg} / \mathrm{kg}\end{array}$}} & \multirow{2}{*}{$\begin{array}{l}\text { TAC } \\
\text { mg Cy-3- } \\
\text { glc/kg }\end{array}$} & \multirow{2}{*}{$\begin{array}{l}\text { Lutein } \\
\mathrm{mg} / \mathrm{kg}\end{array}$} & \multicolumn{2}{|l|}{ Zeaxanthin } \\
\hline & & & $\mathrm{kg} / \mathrm{hL}$ & $\%$ & $\%$ & $\%$ & $\%$ & & & & & & & $\mathrm{mg} / \mathrm{kg}$ & \\
\hline & & $43.6 \mathrm{c}$ & $75.6 \mathrm{~d}$ & $9.1 \mathrm{e}$ & $1.27 \mathrm{c}$ & $14.1 \mathrm{a}$ & $1.01 \mathrm{a}$ & $6.65 \mathrm{a}$ & $1.10 \mathrm{~d}$ & 889 & c & n.d. & $2.18 \mathrm{~b}$ & 0.15 & $\mathrm{~d}$ \\
\hline White & Whitebear & $46.7 \mathrm{~b}$ & $82.8 \quad a$ & $11.3 \mathrm{~d}$ & $1.56 \mathrm{~b}$ & $15.7 \mathrm{a}$ & 0.99 a & $6.94 \quad a$ & $4.71 \mathrm{a}$ & 776 & e & n.d. & $1.07 \mathrm{e}$ & 0.37 & $a$ \\
\hline Yellow & Bona Vita & $37.0 \mathrm{~d}$ & $79.0 \mathrm{c}$ & 15.1 a & $1.48 \mathrm{~b}$ & $12.8 \quad \mathrm{a}$ & $0.96 \quad$ a & $6.61 \quad a$ & $4.33 \mathrm{ab}$ & 800 & $d$ & n.d. & $3.62 \mathrm{a}$ & 0.34 & $\mathrm{~b}$ \\
\hline Purple & Rosso & $46.4 \quad b$ & $80.4 \quad b$ & $12.4 \mathrm{C}$ & $1.58 \mathrm{~b}$ & $15.1 \mathrm{a}$ & $0.66 \quad b$ & $7.57 \quad \mathrm{a}$ & $3.71 \mathrm{~b}$ & 1071 & b & $102 a$ & $1.67 \mathrm{c}$ & 0.34 & $\mathrm{~b}$ \\
\hline Blue & Skorpion & $50.1 \quad a$ & $74.6 \mathrm{e}$ & $13.0 \mathrm{~b}$ & $1.91 \mathrm{a}$ & $12.7 \mathrm{a}$ & $0.53 \mathrm{c}$ & $6.47 \quad a$ & $2.35 \mathrm{c}$ & 1093 & a & $72 \quad b$ & $1.24 \mathrm{~d}$ & 0.29 & c \\
\hline SEM & & 0.4 & 0.3 & 0.1 & 0.08 & 1.6 & 0.06 & 0.99 & 0.58 & 8 & & 5 & 0.11 & 0.02 & \\
\hline$P(F)$ & & $<0.001$ & $<0.001$ & $<0.001$ & $<0.001$ & 0.109 & $<0.001$ & 0.172 & $<0.001$ & $<0.00$ & & 0.001 & $<0.001$ & $<0.001$ & \\
\hline
\end{tabular}

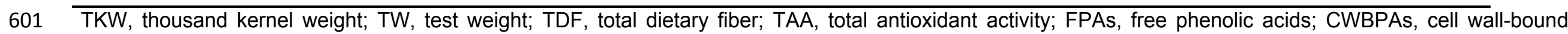
602 phenolic acids; TAC, total anthocyanins.

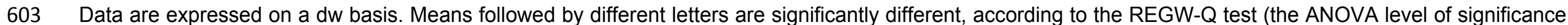
604 is shown in the table).

605 n.d., not detected.

606 SEM, standard error of the mean.

$607{ }^{1}$ sum of the FPAs determined by means of RP-HPLC/DAD

$608{ }^{2}$ sum of the CWBPAs determined by means of RP-HPLC/DAD 
610 Table 2. Chromatic characteristics of the wholegrain flours.

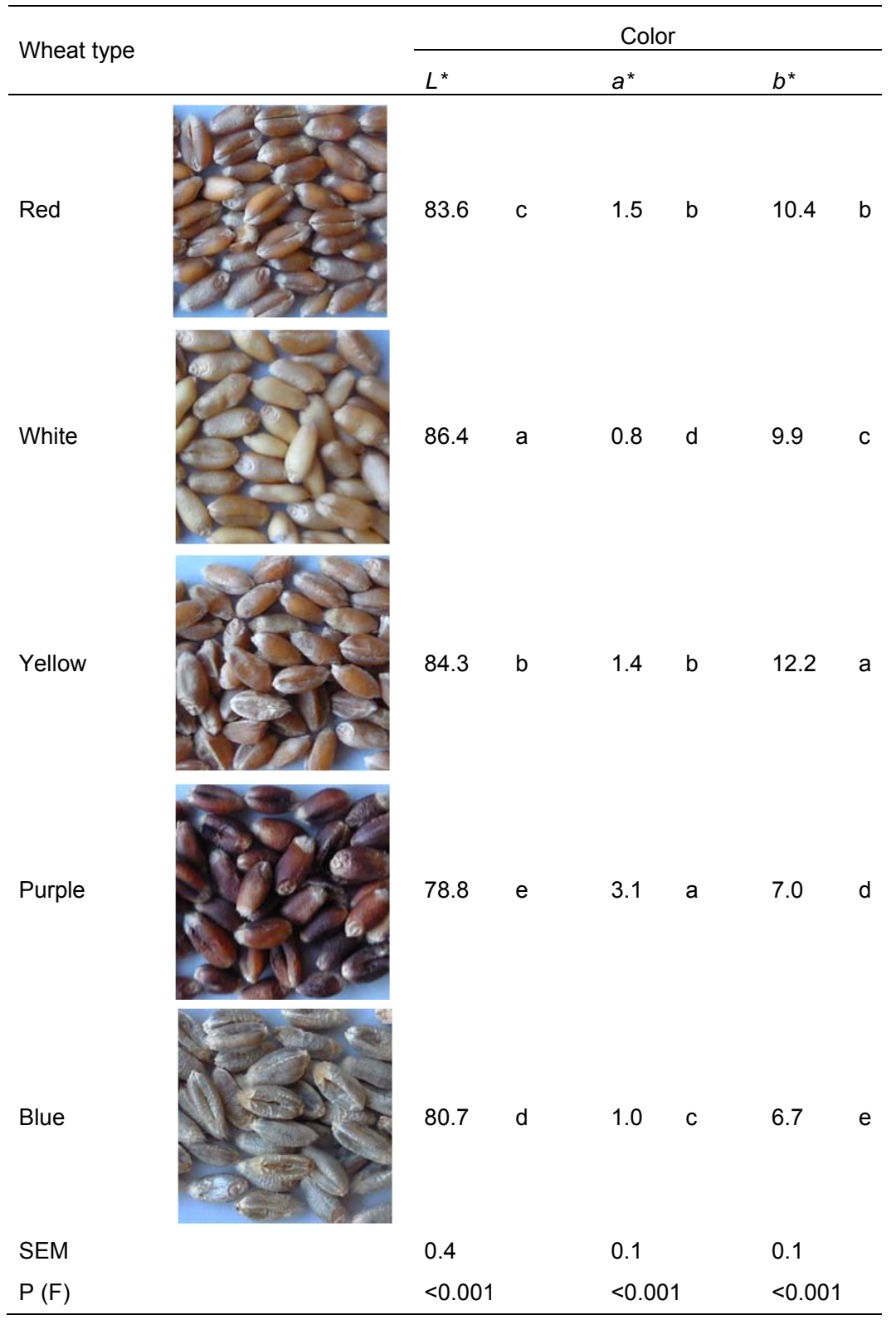

611 Means followed by different letters are significantly different, according to the REGW-Q test (the ANOVA 612 level of significance is shown in the table).

613 SEM, standard error of the mean.

614

615 
616 Table 3. Chemical composition of the roller-milled fractions of conventional and pigmented wheat varieties.

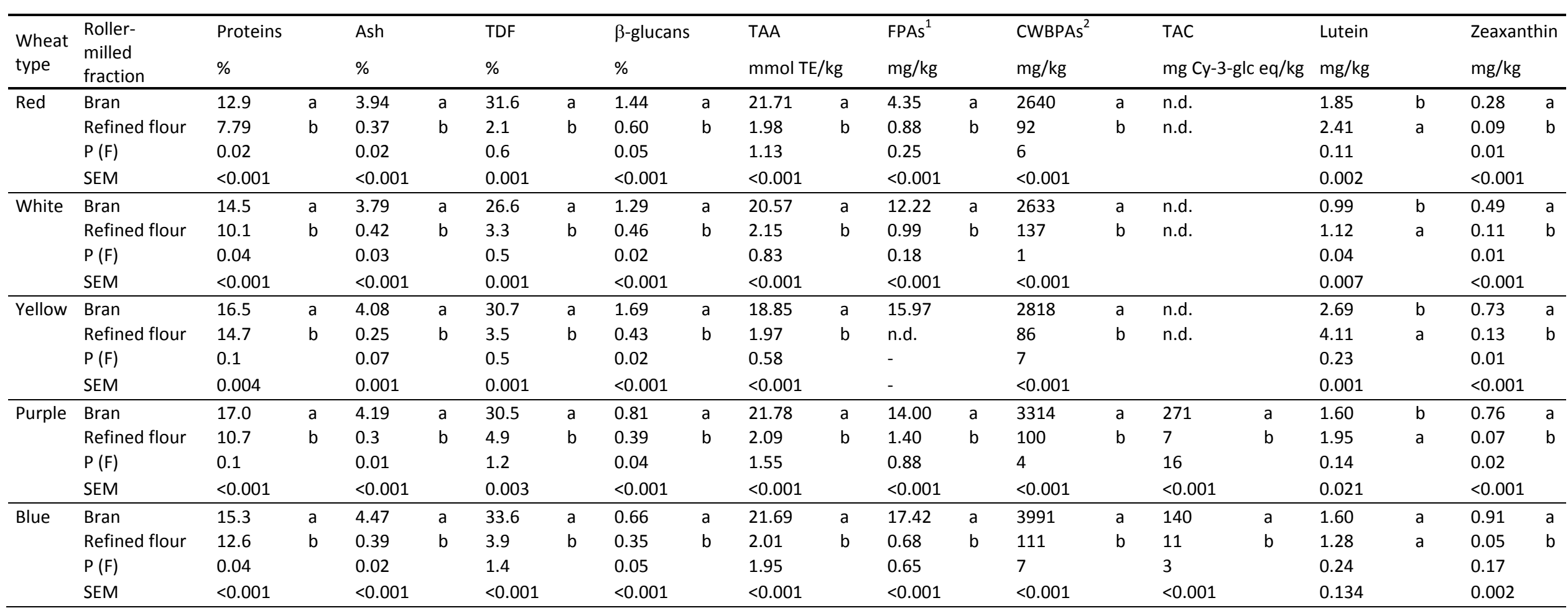

617 TDF, total dietary fiber; TAA, total antioxidant activity; FPAs, free phenolic acids; CWBPAs, cell wall-bound phenolic acids; TAC, total anthocyanins.

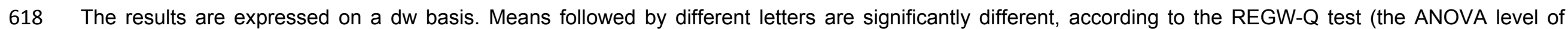
619 significance is shown in the table).

620 n.d., not detected.

621 SEM, standard error of the mean.

$622{ }^{1}$ sum of the FPAs determined by means of RP-HPLC/DAD

$623{ }^{2}$ sum of the CWBPAs determined by means of RP-HPLC/DAD 
Table 4. Chemical composition of the pearled fractions of conventional and pigmented wheat varieties.

\begin{tabular}{|c|c|c|c|c|c|c|c|c|c|c|c|c|c|c|c|c|c|c|c|}
\hline \multirow{2}{*}{$\begin{array}{l}\text { Wheat } \\
\text { type } \\
\text { Red }\end{array}$} & \multirow{2}{*}{$\begin{array}{l}\text { Pearled } \\
\text { fraction }\end{array}$} & \multicolumn{2}{|c|}{$\begin{array}{l}\text { Proteins } \\
\%\end{array}$} & \multicolumn{2}{|l|}{$\begin{array}{l}\text { Ash } \\
\%\end{array}$} & \multicolumn{2}{|l|}{$\begin{array}{l}\text { TDF } \\
\%\end{array}$} & \multicolumn{2}{|c|}{$\begin{array}{l}\beta \text {-glucans } \\
\%\end{array}$} & \multicolumn{2}{|c|}{$\begin{array}{l}\text { TAA } \\
\text { mmol TE/kg }\end{array}$} & \multicolumn{2}{|c|}{$\begin{array}{l}\text { FPAs }^{1} \\
\mathrm{mg} / \mathrm{kg}\end{array}$} & \multicolumn{2}{|c|}{$\begin{array}{l}\text { CWBPAs }^{2} \\
\mathrm{mg} / \mathrm{kg}\end{array}$} & \multicolumn{2}{|c|}{$\begin{array}{l}\text { Lutein } \\
\mathrm{mg} / \mathrm{kg}\end{array}$} & \multicolumn{2}{|c|}{$\begin{array}{l}\text { Zeaxanthin } \\
\mathrm{mg} / \mathrm{kg}\end{array}$} \\
\hline & & 8.7 & c & 3.05 & c & 51.7 & $a$ & 0.99 & c & 18.26 & a & 4.32 & $b c$ & 2327 & a & 1.31 & $d$ & 0.20 & $b$ \\
\hline & $5-10 \%$ & 9.7 & $b$ & 3.07 & c & 38.3 & $b$ & 1.32 & $b$ & 20.09 & $\mathrm{a}$ & 5.96 & $a$ & 2086 & $b$ & 1.35 & $d$ & 0.21 & $b$ \\
\hline & $10-15 \%$ & 10.9 & $\mathrm{a}$ & 3.17 & $b$ & 32.9 & c & 1.52 & $\mathrm{a}$ & 19.40 & a & 5.43 & $a b$ & 1679 & c & 1.64 & c & 0.24 & $a b$ \\
\hline & $15-20 \%$ & 11.1 & $\mathrm{a}$ & 3.29 & $\mathrm{a}$ & 25.5 & $d$ & 1.64 & $\mathrm{a}$ & 12.86 & $b$ & 4.48 & $\mathrm{bc}$ & 1668 & $d$ & 1.76 & bc & 0.22 & $a b$ \\
\hline & $20-25 \%$ & 10.7 & $\mathrm{a}$ & 2.64 & $\mathrm{~d}$ & 21.3 & $\mathrm{e}$ & 1.48 & $a b$ & 10.55 & $b$ & 5.30 & $a b$ & 1419 & e & 2.03 & $b$ & 0.25 & a \\
\hline & $25-100 \%$ & 9.0 & $c$ & 1.17 & $\mathrm{e}$ & 9.5 & $f$ & 0.60 & $d$ & 3.65 & c & 3.71 & $\mathrm{c}$ & 449 & $f$ & 2.55 & $\mathrm{a}$ & 0.15 & c \\
\hline & SEM & 0.4 & & 0.04 & & 1.8 & & 0.12 & & 2.14 & & 0.92 & & 6 & & 0.24 & & 0.03 & \\
\hline & $P(F)$ & $<0.00$ & & $<0.00$ & & $<0.00$ & & $<0.00$ & & $<0.001$ & & 0.001 & & $<0.001$ & & $<0.00$ & & $<0.001$ & \\
\hline \multirow[t]{8}{*}{ White } & $0-5 \%$ & 11.0 & $d$ & 5.04 & $b$ & 65.1 & $a$ & 1.19 & c & 22.62 & $\mathrm{a}$ & 12.90 & a & 3040 & $a$ & 0.73 & c & 0.88 & $a$ \\
\hline & $5-10 \%$ & 15.4 & $b$ & 5.21 & $a$ & 31.1 & $b$ & 1.77 & $\mathrm{a}$ & 20.95 & $\mathrm{a}$ & 9.58 & $b$ & 2892 & $b$ & 0.94 & $b$ & 0.90 & a \\
\hline & $10-15 \%$ & 15.9 & $a$ & 4.14 & c & 26.9 & bc & 1.45 & $b$ & 11.19 & $b$ & 9.53 & $b$ & 2026 & $c$ & 1.05 & $a b$ & 0.77 & b \\
\hline & $15-20 \%$ & 15.1 & $c$ & 3.17 & $d$ & 25.3 & c & 1.16 & c & 9.54 & $b$ & 6.53 & c & 1697 & $d$ & 1.10 & $\mathrm{a}$ & 0.70 & $b$ \\
\hline & $20-25 \%$ & 15.4 & $b$ & 2.58 & $\mathrm{e}$ & 18.5 & $d$ & 0.99 & $d$ & 7.21 & c & 6.50 & c & 1312 & $\mathrm{e}$ & 1.14 & $\mathrm{a}$ & 0.60 & c \\
\hline & $25-100 \%$ & 10.5 & $\mathrm{e}$ & 0.96 & $f$ & 8.8 & $\mathrm{e}$ & 0.24 & $\mathrm{e}$ & 2.21 & $d$ & 3.01 & $d$ & 361 & $f$ & 1.01 & $a b$ & 0.20 & d \\
\hline & SEM & 0.2 & & 0.07 & & 2.2 & & 0.15 & & 3.15 & & 0.87 & & 7 & & 0.12 & & 0.08 & \\
\hline & $P(F)$ & $<0.00$ & & $<0.00$ & & $<0.00$ & & $<0.00$ & & $<0.001$ & & $<0.00$ & & $<0.001$ & & $<0.00$ & & $<0.001$ & \\
\hline \multirow[t]{8}{*}{ Yellow } & $0-5 \%$ & 13.4 & $d$ & 4.25 & $a$ & 59.0 & $a$ & 1.65 & $b$ & 24.41 & a & 14.02 & $\mathrm{a}$ & 3088 & $a$ & 1.37 & c & 0.78 & b \\
\hline & $5-10 \%$ & 20.6 & $b$ & 3.82 & $b$ & 35.1 & $b$ & 2.26 & $\mathrm{a}$ & 20.34 & $b$ & 9.67 & $b$ & 3052 & $b$ & 3.10 & $b$ & 0.98 & $a$ \\
\hline & $10-15 \%$ & 21.8 & $a$ & 2.99 & $c$ & 23.4 & c & 1.90 & $b$ & 16.08 & c & 7.59 & c & 2199 & $c$ & 3.65 & $a b$ & 0.83 & b \\
\hline & $15-20 \%$ & 20.7 & $b$ & 2.35 & $d$ & 16.9 & $d$ & 1.13 & c & 9.26 & $d$ & 5.23 & $d$ & 1533 & $d$ & 3.74 & $\mathrm{a}$ & 0.61 & c \\
\hline & $20-25 \%$ & 20.8 & $b$ & 1.95 & e & 13.8 & de & 1.01 & c & 6.41 & $\mathrm{e}$ & 3.88 & $d$ & 1079 & e & 3.70 & $\mathrm{a}$ & 0.49 & d \\
\hline & $25-100 \%$ & 13.8 & $c$ & 0.88 & $f$ & 9.3 & $\mathrm{e}$ & 0.24 & $d$ & 2.43 & $f$ & 1.75 & $\mathrm{e}$ & 526 & $f$ & 4.12 & a & 0.23 & e \\
\hline & SEM & 0.2 & & 0.07 & & 2.5 & & 0.23 & & 3.11 & & 1.24 & & 20 & & 0.49 & & 0.06 & \\
\hline & $P(F)$ & $<0.00$ & & $<0.00$ & & $<0.00$ & & $<0.00$ & & $<0.001$ & & $<0.00$ & & $<0.001$ & & $<0.00$ & & $<0.001$ & \\
\hline \multirow[t]{8}{*}{ Purple } & $0-5 \%$ & 11.4 & $\mathrm{~d}$ & 3.11 & $c$ & 49.8 & $a$ & 0.56 & $b$ & 26.40 & $\mathrm{a}$ & 16.69 & $a$ & 2632 & $b$ & 1.12 & $b$ & 0.75 & $\mathrm{a}$ \\
\hline & $5-10 \%$ & 12.5 & $c$ & 3.60 & $a$ & 42.0 & $b$ & 0.83 & $a$ & 23.63 & $b$ & 16.28 & $\mathrm{a}$ & 2800 & $a$ & 1.20 & $b$ & 0.66 & bc \\
\hline & $10-15 \%$ & 14.6 & $b$ & 3.62 & $a$ & 34.3 & c & 0.84 & $\mathrm{a}$ & 17.48 & c & 11.38 & $b$ & 2623 & $b$ & 1.62 & $\mathrm{a}$ & 0.73 & $a b$ \\
\hline & $15-20 \%$ & 15.2 & $a$ & 3.49 & $b$ & 26.0 & $d$ & 0.82 & $\mathrm{a}$ & 12.03 & $d$ & 8.98 & c & 1863 & c & 1.66 & $\mathrm{a}$ & 0.60 & c \\
\hline & $20-25 \%$ & 15.1 & $\mathrm{a}$ & 3.14 & $c$ & 21.9 & $d$ & 0.82 & $a$ & 9.34 & e & 7.31 & $d$ & 1797 & $d$ & 1.62 & $\mathrm{a}$ & 0.49 & d \\
\hline & $25-100 \%$ & 12.5 & c & 1.47 & $d$ & 12.1 & e & 0.22 & c & 3.15 & $f$ & 2.63 & e & 733 & $\mathrm{e}$ & 1.59 & $\mathrm{a}$ & 0.19 & e \\
\hline & SEM & 0.3 & & 0.08 & & 1.8 & & 0.17 & & 1.61 & & 1.2 & & 12 & & 0.15 & & 0.08 & \\
\hline & $P(F)$ & $<0.00$ & & $<0.00$ & & $<0.00$ & & $<0.00$ & & $<0.001$ & & $<0.00$ & & $<0.001$ & & $<0.00$ & & $<0.001$ & \\
\hline \multirow[t]{8}{*}{ Blue } & $0-5 \%$ & 9.9 & $f$ & 3.57 & $c$ & 59.9 & $a$ & 0.52 & c & 23.11 & a & 11.16 & a & 5388 & $a$ & 0.93 & $c$ & 0.52 & b \\
\hline & $5-10 \%$ & 14.9 & d & 4.31 & $a$ & 37.6 & $b$ & 1.09 & $a$ & 16.64 & $b$ & 6.16 & $b$ & 3452 & $b$ & 1.15 & $b$ & 0.66 & $\mathrm{a}$ \\
\hline & $10-15 \%$ & 17.7 & $b$ & 4.59 & $\mathrm{a}$ & 27.8 & $c$ & 1.03 & $a$ & 15.25 & $b$ & 5.10 & bc & 2913 & $c$ & 1.36 & $a b$ & 0.67 & $\mathrm{a}$ \\
\hline & $15-20 \%$ & 18.1 & $\mathrm{a}$ & 3.98 & $b$ & 21.2 & $d$ & 0.85 & $b$ & 10.92 & c & 4.13 & c & 2243 & $d$ & 1.51 & a & 0.63 & $\mathrm{a}$ \\
\hline & $20-25 \%$ & 17.5 & $c$ & 3.32 & $c$ & 15.8 & e & 0.82 & $b$ & 8.04 & $\mathrm{~d}$ & 5.13 & bc & 1890 & e & 1.46 & $\mathrm{a}$ & 0.51 & $b$ \\
\hline & $25-100 \%$ & 12.5 & $\mathrm{e}$ & 0.98 & $\mathrm{~d}$ & 8.0 & $f$ & 0.24 & $d$ & 2.48 & e & 2.51 & $d$ & 622 & $f$ & 1.32 & $a b$ & 0.20 & c \\
\hline & SEM & 0.2 & & 0.27 & & 1 & & 0.17 & & 2.92 & & 0.95 & & 11 & & 0.18 & & 0.09 & \\
\hline & $P(F)$ & $<0.00$ & & $<0.00$ & & $<0.00$ & & $<0.00$ & & $<0.001$ & & $<0.00$ & & $<0.001$ & & $<0.00$ & & $<0.001$ & \\
\hline
\end{tabular}

TDF, total dietary fiber; TAA, total antioxidant activity; FPAs, free phenolic acids; CWBPAs, cell wall-bound phenolic acids; TAC, total anthocyanins. 
The results are expressed on a dw basis. Means followed by different letters are significantly different, according to the REGW-Q test (the ANOVA level of significance is shown in the table).

SEM, standard error of the mean.

${ }^{1}$ sum of the FPAs determined by means of RP-HPLC/DAD

${ }^{2}$ sum of the CWBPAs determined by means of RP-HPLC/DAD 
1 Table 5. Anthocyanin profile in the pearled fractions of the purple- and blue-grained wheat 2 varieties.

\begin{tabular}{|c|c|c|c|c|c|c|c|c|c|c|c|c|c|}
\hline \multirow{3}{*}{$\begin{array}{l}\text { Wheat type } \\
\text { Purple }\end{array}$} & \multirow{3}{*}{$\begin{array}{l}\text { Pearled fraction } \\
0-5 \%\end{array}$} & \multicolumn{2}{|c|}{$C y-3-g l c$} & \multicolumn{2}{|c|}{ Cy-3-rut } & \multicolumn{2}{|c|}{ Dn-3-glc } & \multicolumn{2}{|c|}{ Dn-3-rut } & \multicolumn{2}{|c|}{ Pn-3-glc } & \multicolumn{2}{|c|}{ Pn-3-rut } \\
\hline & & \multicolumn{12}{|c|}{$\mathrm{mg} / \mathrm{kg}$} \\
\hline & & 4.15 & $\mathrm{a}$ & 3.62 & $\mathrm{a}$ & n.d. & & n.d. & & 1.03 & $a$ & 9.36 & a \\
\hline & $5-10 \%$ & 2.72 & $b$ & 2.89 & $b$ & n.d. & & n.d. & & 0.72 & $b$ & 6.72 & $b$ \\
\hline & $10-15 \%$ & 1.47 & c & 1.76 & c & n.d. & & n.d. & & 0.47 & c & 3.71 & c \\
\hline & $15-20 \%$ & 0.95 & $d$ & 1.15 & $d$ & n.d. & & n.d. & & 0.29 & $d$ & 2.81 & $d$ \\
\hline & $20-25 \%$ & 0.71 & $d$ & 0.58 & e & n.d. & & n.d. & & 0.20 & $d$ & 1.44 & e \\
\hline & $25-100 \%$ & 0.13 & $\mathrm{e}$ & 0.11 & $f$ & n.d. & & \multicolumn{2}{|l|}{ n.d. } & \multicolumn{2}{|l|}{ n.d. } & 0.13 & $f$ \\
\hline & SEM & \multicolumn{2}{|l|}{0.13} & \multicolumn{4}{|l|}{0.32} & & & 0.06 & & \multicolumn{2}{|l|}{0.53} \\
\hline & $P(F)$ & \multicolumn{2}{|c|}{$<0.001$} & \multicolumn{2}{|l|}{$<0.001$} & \multicolumn{2}{|l|}{-} & \multicolumn{2}{|l|}{ - } & \multicolumn{2}{|c|}{$<0.001$} & \multicolumn{2}{|c|}{$<0.001$} \\
\hline \multirow[t]{8}{*}{ Blue } & $0-5 \%$ & 1.32 & c & 5.62 & c & 1.47 & c & 4.62 & c & n.d. & & 0.40 & $c$ \\
\hline & $5-10 \%$ & 3.75 & $\mathrm{a}$ & 12.62 & $\mathrm{a}$ & 3.06 & $a b$ & 10.26 & a & n.d. & & 0.98 & $a b$ \\
\hline & $10-15 \%$ & 3.79 & a & 12.85 & a & 3.34 & $a$ & 10.85 & a & n.d. & & 1.13 & $\mathrm{a}$ \\
\hline & $15-20 \%$ & 2.55 & $b$ & 10.56 & $b$ & 2.77 & $b$ & 8.94 & $b$ & n.d. & & 0.92 & $b$ \\
\hline & $20-25 \%$ & 2.69 & b & 10.33 & $b$ & 2.85 & $b$ & 9.17 & $b$ & n.d. & & 0.98 & $a b$ \\
\hline & $25-100 \%$ & 0.18 & $d$ & 1.15 & $d$ & 0.37 & $d$ & 1.15 & $d$ & n.d. & & 0.30 & $c$ \\
\hline & SEM & \multicolumn{2}{|l|}{0.33} & \multicolumn{2}{|l|}{1.08} & \multicolumn{2}{|l|}{0.32} & \multicolumn{2}{|l|}{0.81} & & & \multicolumn{2}{|l|}{0.12} \\
\hline & $P(F)$ & \multicolumn{2}{|c|}{$<0.001$} & \multicolumn{2}{|l|}{$<0.001$} & \multicolumn{2}{|c|}{$<0.001$} & \multicolumn{2}{|l|}{$<0.001$} & \multicolumn{2}{|l|}{ - } & \multicolumn{2}{|c|}{$<0.001$} \\
\hline
\end{tabular}

3 Cy-3-glc, cyanidin-3-O-glucoside; Cy-3-rut, cyanidin-3-O-rutinoside; Dn-3-glc, delphinidin-3-O-glucoside; Dn4 3-rut, delphinidin-3-O-rutinoside; Pn-3-glc, peonidin-3-O-glucoside; Pn-3-rut, peonidin-3-O-rutinoside.

5 The results are expressed on a dw basis. Means followed by different letters are significantly different, 6 according to the REGW-Q test (the ANOVA level of significance is shown in the table).

7 n.d., not detected

8 SEM, standard error of the mean. 
